\title{
EL CONTENIDO CONSTITUCIONALMENTE PROTEGIDO SEGÚN EL INCISO 1 DEL ARTÍCULO 5 DEL CÓDIGO PROCESAL CONSTITUCIONAL
}

\section{THE CONSTITUTIONALLY PROTECTED CONTENT ACCORDING TO SECTION 1 OF ARTICLE 5 OF THE CONSTITUTIONAL CODE OF PROCEDURE}

\author{
Francisco Morales Saravia \\ Profesor de Derecho Constitucional y Procesal Constitucional \\ Universidad de San Martín de Porres \\ fmorales_s@yahoo.com
} Perú

\section{SUMARIO}

- Introducción

- Finalidad y procedencia del proceso de amparo

- Causales de improcedencia del proceso de amparo

- Determinación del contenido constitucionalmente protegido de un derecho conforme a la doctrina y a la jurisprudencia constitucional

- Conclusión

\section{RESUMEN}

En el presente artículo se analizará la causal de improcedencia del proceso de amparo establecida en el inciso 1 del artículo $5 \mathrm{del}$ Código Procesal Constitucional del Perú. Se presentarán brevemente los rasgos esenciales del proceso de amparo y las causales de improcedencia. Del mismo modo se hará referencia a las divergencias doctrinarias para definir el contenido constitucionalmente y se explicará por qué conforme a la Cuarta disposición final y transitoria de la Constitución y al artículo $\mathrm{V}$ del Título Preliminar del Código Procesal Constitucional sí es posible configurar operativamente el contenido constitucional de un derecho tal como lo ha efectuado en Tribunal Constitucional del Perú en varios casos.

\footnotetext{
ABSTRACT

This article will analyze the grounds of inadmissibility of the amparo process
}

established in paragraph 1 of article 5 of the Peruvian Constitutional Procedural Code. The essential features of the amparo process and the grounds of inadmissibility will be briefly presented. Likewise, reference will be made to doctrinal divergences to define the constitutional content and will be explained by the fact that according to the Fourth Final and Transitional Provision of the Constitution and Article $\mathrm{V}$ of the Preliminary Title of the Constitutional Procedural Code, it is possible to configure the constitutional content of a right such as it has done in Constitutional Court of Peru in several cases.

\section{PALABRAS CLAVE}

Contenido constitucionalmente protegido de un derecho. Proceso de amparo. Causales de improcedencia del proceso de amparo.

\section{KEYWORDS}

Constitutional content protected from a right. Amparo process. Causes of inadmissibility of the amparo process.

\section{INTRODUCCIÓN}

El Código Procesal Constitucional del año 2004 cambió, radicalmente, la configuración del proceso de amparo pasando de un modelo alternativo a uno residual o excepcional que considera condiciones o requisitos más exigentes para plantear una demanda de amparo. De todas ellas, dos destacan por su carácter indeterminado, a veces subjetivo, 
y por su alta incidencia para que los Jueces constitucionales declaren la improcedencia de los procesos de amparo. Me refiero al contenido constitucionalmente protegido de un derecho y a la existencia de vías procedimentales específicas, igualmente satisfactorias para la protección de un derecho, ambas reguladas en los incisos 1 y 2 del artículo 5 del Código Procesal Constitucional.

En esta oportunidad nos referiremos a la determinación del contenido constitucionalmente protegido de un derecho, dado que es el primer paso para la procedencia de un proceso de amparo en el esquema residual, esto es, saber si los hechos y el petitorio están referidos en forma directa a dicho contenido. Si no es así la demanda será declarada improcedente. Cumplida esa primera condición, el segundo paso es saber si existen vías procedimentales específicas, igualmente satisfactorias al amparo para la protección del derecho, de existir, la demanda también será improcedente. Como podemos apreciar se trata de dos requisitos fundamentales para la viabilidad del proceso de amparo.

La doctrina nacional y la jurisprudencia constitucional han caracterizado ambas condiciones. Sin embargo, en relación a la primera, hasta el día de hoy, no podemos afirmar que exista una única postura para precisar que debemos entender por el concepto de contenido constitucionalmente protegido de un derecho. En relación a la jurisprudencia ésta ha sido cambiante en relación a perfilar una definición exacta. A continuación ensayaremos una propuesta a fin de enriquecer este debate.

\section{FINALIDAD Y PROCEDENCIA DEL PROCESO DE AMPARO}

El artículo 1 del Código Procesal Constitucional establece que el proceso de amparo tiene por finalidad proteger los derechos constitucionales, reponiendo las cosas al estado anterior a la violación o amenaza de un derecho constitucional. ${ }^{1}$ Añade la norma, que si luego de presentada la demanda cesa la agresión o amenaza por decisión voluntaria del agresor,

\footnotetext{
1 Por ejemplo, en el caso de un trabajador despedido, si se comprueba que dicho acto lesivo vulneró su derecho al trabajo o algún otro derecho constitucional, sólo a través de su reposición en el puesto de trabajo se podrá reponer la situación al estado anterior a la violación de tal derecho.
}

o si ella deviene en irreparable ${ }^{2}$, el Juez, atendiendo al agravio producido, declarará fundada la demanda precisando los alcances de su decisión, disponiendo que el emplazado no vuelva a incurrir en las acciones u omisiones que motivaron la interposición de la demanda, y que si procediere de modo contrario se le aplicarán las medidas coercitivas previstas en el artículo 22 del mismo Código, sin perjuicio de la responsabilidad penal que corresponda. ${ }^{3}$

El inciso 2 del artículo 200 de la Constitución dispone que la acción de amparo procede contra el hecho u omisión, por parte de cualquier autoridad, funcionario o persona, que vulnera o amenaza los derechos reconocidos por la Constitución, con excepción de los protegidos por los procesos de hábeas corpus y de hábeas data. También señala que no procede contra normas legales ni contra resoluciones judiciales emanadas de procedimiento regular.

Desarrollando la norma constitucional citada los artículos 2 y 3 del Código Procesal Constitucional disponen:

- Procede el proceso de amparo cuando se amenace o viole los derechos constitucionales por acción u omisión por parte de cualquier autoridad, funcionario o persona.

- Cuando se invoque la amenaza de violación, ésta debe ser cierta y de inminente realización.

- Cuando se invoque la amenaza o violación de actos que tienen como sustento la aplicación de una norma autoaplicativa incompatible con la Constitución, la sentencia que declare fundada la demanda dispondrá además la inaplicabilidad de la citada norma. ${ }^{4}$

Para el caso del proceso de amparo contra resoluciones judiciales el artículo 4 del Código Procesal Constitucional establece:

2 Ejemplo de este supuesto lo encontramos en el caso Gregorio Dennis Chávez de Paz (Exp. N. ${ }^{\circ}$ 02282-2013-PA/TC), donde se declaró fundada la demanda en aplicación del segundo párrafo del artículo 1 del Código Procesal Constitucional, por un despido que violó el derecho al debido proceso, pero como el mandato del cargo había vencido, el TC comprobó una situación de irreparabilidad.

3 El artículo 22 del Código Procesal Constitucional prevé como medidas coercitivas las multas fijas o acumulativas o la destitución del responsable.

4 El artículo 3 del Código Procesal Constitucional define las normas autoaplicativas como aquellas cuya aplicabilidad, una vez que han entrado en vigencia, resulta inmediata e incondicionada. 
- El amparo procede respecto de resoluciones judiciales firmes dictadas con manifiesto agravio a la tutela procesal efectiva, que comprende el acceso a la justicia y el debido proceso. ${ }^{5}$

- Es improcedente cuando el agraviado dejó consentir la resolución que dice afectarlo.

El proceso de amparo procederá contra una sentencia expedida por la jurisdicción ordinaria (Poder Judicial) siempre que se invoque la violación de la tutela procesal efectiva, el derecho de acceso a la justicia o el debido proceso. Sin embargo, el Tribunal Constitucional en el caso Apolonia Collcca Ponce, Exp. N. ${ }^{\circ} 3179$ 2004-AA/TC, estableció que el amparo contra resoluciones judiciales también procede cuando se viole cualquier otro derecho constitucional, además de los derechos de acceso a la justicia y debido proceso. En otras palabras, también procederá un proceso de amparo contra una resolución judicial, por violación de un derecho constitucional cualquiera.

Como podemos apreciar el diseño constitucional y legal del proceso de amparo es bastante completo y constituye, sin duda, una vía idónea para la protección y vigencia efectiva de los derechos fundamentales garantizados por la Constitución. Ahora bien, el primer paso para poner en marcha el mecanismo de la jurisdicción constitucional destinado a la garantía de los derechos constitucionales es superar las causales de improcedencia del Proceso de amparo reguladas en la Ley.

\section{CAUSALES DE IMPROCEDENCIA DEL PROCESO DE AMPARO}

El artículo 5 del Código Procesal Constitucional establece las causales de improcedencia de los procesos de amparo. Los siguientes supuestos establecen que la demanda no procede cuando:

- Los hechos y el petitorio de la demanda no están referidos en forma directa al contenido constitucionalmente protegido del derecho invocado (inciso 1).

5 El artículo 4 del CPConst. define la tutela procesal efectiva como aquella situación jurídica de una persona en la que se respetan, de modo enunciativo, sus derechos de libre acceso al órgano jurisdiccional, a probar, de defensa, al contradictorio e igualdad sustancial en el proceso, a no ser desviado de la jurisdicción predeterminada ni sometido a procedimientos distintos de los previstos por la ley, a la obtención de una resolución fundada en derecho, a acceder a los medios impugnatorios regulados, a la imposibilidad de revivir procesos fenecidos, a la actuación adecuada y temporalmente oportuna de las resoluciones judiciales y a la observancia del principio de legalidad penal.
- Existan vías procedimentales específicas, igualmente satisfactorias, para la protección del derecho constitucional amenazado o vulnerado, salvo cuando se trate del proceso de hábeas corpus (inciso 2).

- El agraviado haya recurrido previamente a otro proceso judicial para pedir tutela respecto de su derecho constitucional (inciso 3).

- No se hayan agotado las vías previas, salvo en los casos previstos en el Código y en el proceso de hábeas corpus (inciso 4).

- A la presentación de la demanda ha cesado la amenaza o violación de un derecho constitucional o se ha convertido en irreparable (inciso 5).

- Se cuestione una resolución firme recaída en otro proceso constitucional o haya litispendencia (inciso 6).

- Se cuestionen las resoluciones definitivas del Consejo Nacional de la Magistratura en materia de destitución y ratificación de jueces y fiscales, siempre que dichas resoluciones hayan sido motivadas y dictadas con previa audiencia al interesado (inciso 7).

- Se trate de conflictos entre entidades de derecho público interno. Los conflictos constitucionales surgidos entre dichas entidades, sean poderes del Estado, órganos de nivel o relevancia constitucional, gobiernos locales y regionales, serán resueltos por las vías procedimentales correspondientes (inciso 9).

- Ha vencido el plazo para interponer la demanda, con excepción del proceso de habeas corpus (inciso 10).

Todas estas causales de improcedencia tienen como finalidad dar un orden y racionalidad al uso del mecanismo procesal del amparo. Sólo después de cumplir las citadas condiciones la demanda se encontrará expedita para ser tramitada. Las dos primeras causales de improcedencia citadas son las más indeterminadas, generales y las más usadas por los jueces. Han propiciado un amplio desarrollo doctrinario y jurisprudencial en nuestro país que está lejos de acabar. Como dijimos al inicio, solo nos referiremos a la primera, ya que su configuración constituye también un aspecto central de la teoría general de los derechos fundamentales. 


\section{DETERMINACIÓN DEL CONTENIDO CONSTITUCIONALMENTE PROTEGIDO DE UN DERECHO CONFORME A LA DOCTRINA Y A LA JURISPRUDENCIA CONSTITUCIONAL}

El inciso 1 del artículo 5 del Código Procesal Constitucional establece que no procede el proceso de amparo si los hechos y el petitorio de la demanda no están referidos en forma directa al contenido constitucionalmente protegido del derecho invocado.

Sobre esta causal Figueroa, E. (2015) explica que mucho de lo determinado a nivel de la justicia constitucional ha sido expresado en clave negativa, en el sentido de que las situaciones analizadas en estos supuestos no inciden en un nivel de gravedad manifiesto en el ámbito del contenido constitucionalmente protegido. En efecto, el autor citado demuestra como el Tribunal Constitucional rechazó varias demandas argumentando que no se referían al contenido constitucionalmente protegido del derecho invocado pero sin explicar cuál era el contenido del derecho invocado. La observación de Figueroa es cierta, sin embargo, como veremos más adelante el Tribunal Constitucional en otros casos sí ensayó una forma de configurar el contenido constitucionalmente protegido de determinados derechos, sobre todo en el ámbito laboral.

A nivel de la doctrina nacional no es pacífica la delimitación conceptual de lo que debe entenderse por contenido constitucionalmente protegido de un derecho. Así Mesía C. (2013) considera que tal expresión se identifica con la de contenido esencial de un derecho. ${ }^{6}$ Por su parte Abad, S. (2017) postula que dicho concepto es distinto al de "contenido esencial" de un derecho fundamental. ${ }^{7}$ Castillo, L. (2006) también es crítico de trasladar la tesis europea del contenido esencial a nuestro medio, pero por razones distintas a las de Samuel Abad, y

\footnotetext{
6 Mesía (2013 p. 241) dice: [...] son improcedentes los procesos constitucionales cuya demanda está referida a aspectos secundarios y accesorios del derecho constitucional que no son parte de su contenido esencial.

7 Abad (2017 p. 108) dice: Cuando se elaboró el Anteproyecto de Código lo que se trató de evitar con dicha expresión fue la extensión indebida del contenido de un derecho fundamental para forzar el empleo del amparo. No se pretendió trasladar la tesis del "contenido esencial" para explicarlo, sino tan solo fijar un criterio general que contribuya a evitar excesos y que el juez en los casos que lleguen a su conocimiento pueda ir determinando. En la citada obra desarrolla ampliamente las razones de su postura, págs. 108 a 110.
}

plantea la tesis del contenido limitado de los derechos, los cuales serían absolutos y que todo su contenido sería esencial. ${ }^{8}$ La jurisprudencia del Tribunal Constitucional, en muchos casos, ha adoptado la tesis del contenido esencial de los derechos de raigambre europea (sobre todo la desarrollada en Alemania y España) equiparado ambas expresiones. ${ }^{9}$

Frente a este panorama proponemos un nivel interpretativo para perfilar el contenido constitucional protegido de un derecho que tiene dos componentes. El primero, seguirá la propuesta de Freixes desde la perspectiva de la doctrina constitucional y el segundo se refiere a la normativa constitucional sobre la interpretación de los derechos fundamentales (IV Disp. Final y Transitoria de la Cons. y Art. V del Título Preliminar del Código Procesal Constitucional).

Freixes, T. (1998) establece que uno de los elementos configuradores de los derechos fundamentales es el contenido de un derecho. ${ }^{10}$ Así, la Catedrática de Derecho Constitucional de la Universidad Autónoma de Barcelona nos dice:
[...] si consideramos a los derechos fundamentales como instituciones jurídicas constitucionales dotadas de un contenido propio, necesariamente hemos de hacer referencia al objeto o a los bienes jurídicos subyacentes a tal institución, especialmente para poder determinar las potestades de acción que el derecho en cuestión otorgará a sus titulares a los efectos de que puedan ejercitarlo dentro de los límites constitucionalmente admitidos. El contenido de los derechos fundamentales vendría así definido en relación a los intereses sociales protegidos en el momento concreto que se proceda a su juridificación, entendiendo, eso sí, que tales intereses pueden evolucionar $y$ originar variaciones en el régimen jurídico de la institución mientras los cambios no alteren su propia naturaleza.

8 Castillo (2006 ps. 591 a 599).

9 Por todas ver el precedente constitucional recaído en el caso Anicama Hernández, Exp. N. ${ }^{\circ} 01417-2005-A A / T C$.

10 Freixes (1998 ps. 150 a 166), desde una perspectiva de la Teoría institucional de los derechos, ha establecido los siguientes elementos configuradores de los derechos fundamentales: Estructura jurídica, función de los derechos, titularidad de los derechos, contenido de los derechos, ejercicio de los derechos, límites a los derechos, garantías de los derechos y suspensión de los derechos. 


\begin{abstract}
[...] la definición del contenido de los derechos como elemento configurador (el contenido es uno de los elementos configuradores) clarifica lo que es en sí el derecho fundamental que se esté analizando en cada momento concreto, puesto que al determinar el bien jurídico que le subyace identificamos aquello sin lo cual el derecho pierde su objeto, determinación de suma importancia para efectuar el juicio de constitucionalidad sobre la interpretación, tanto legal como jurisdiccional o de aplicación administrativa, que deba otorgarse al derecho constitucional controvertido.
\end{abstract}

Este planteamiento nos puede ayudar a perfilar el contenido de un derecho, sobre todo porque pone énfasis en los intereses o bienes jurídicos que subyacen en determinado derecho y nos pide identificar las características sin las cuales tal derecho pierde su objeto o deja de ser tal. Además, el enfoque de Freixes destaca el carácter evolutivo de los derechos, que no hay un contenido absoluto inmutable y permanente en el tiempo. Desde la perspectiva institucional de los derechos los intereses que protegen los derechos pueden variar y con ello también su régimen jurídico.

Este planteamiento doctrinario se complementa con las reglas de nuestro ordenamiento constitucional y legal que establecen pautas obligatorias para configurar el contenido de un derecho constitucional a través de lo que se conoce como la "interpretación conforme con los tratados internacionales de derechos humanos", la cual ha sido seguida por el Tribunal Constitucional en varios casos que citaremos más adelante.

La primera regla obligatoria de interpretación es la Cuarta disposición final y transitoria de la Constitución, que establece lo siguiente: las normas relativas a los derechos y a las libertades que la Constitución reconoce se interpretan de conformidad con la Declaración Universal de Derechos Humanos y con los tratados y acuerdos internacionales de derechos humanos ratificados por el Perú. Es decir, la interpretación y por ende la definición del contenido de los derechos y la identificación de sus elementos configuradores debe hacerse en primer lugar a partir de la Constitución y los tratados internacionales de derechos humanos. Complementada por la Jurisprudencia del Tribunal Constitucional conforme a los mandatos constitucionales y legales pertinentes (LOTC, Cod. Proc. Const.).

El segundo mandato obligatorio de interpretación de los derechos, que desarrolla la Cuarta disposición final y transitoria de la Constitución, es el artículo $\mathrm{V}$ del Título Preliminar del Código Procesal Constitucional que dispone: el contenido y alcances de los derechos constitucionales protegidos por los procesos regulados en dicho código deben interpretarse de conformidad con la Declaración Universal de Derechos Humanos, los tratados sobre derechos humanos, así como de las decisiones adoptadas por los tribunales internaciones sobre derechos humanos constituidos según tratados de los que el Perú sea parte. Esta norma complementa la anterior y especifica claramente que la interpretación sirve para perfilar el contenido del derecho constitucional, con lo cual tenemos que el concepto de "contenido constitucionalmente protegido" del inciso 1 del artículo 5 del Código Procesal Constitucional deber necesariamente concordarse e interpretarse con el artículo V del mismo texto legal. Asimismo, por mandato de esta norma la Jurisprudencia de la Corte Interamericana de Derechos Humanos también servirá para delimitar el contenido del derecho.

Estas normas constituyen un mandato constitucional y legal de obligatorio cumplimiento para efectuar la interpretación de los derechos constitucionales y definir el contenido de un derecho fundamental. Tales principios interpretativos del más alto rango constitucional configuran lo que se denomina parámetro de constitucionalidad o canon de constitucionalidad para la interpretación de los derechos fundamentales, hoy pacíficamente aceptados y cada vez más difundidos en nuestro medio, y que según Remotti, J. (2009) están conformados por $^{11}$ :

\footnotetext{
11 Sobre el parámetro de constitucionalidad Remotti (2009 p. XXXV) dice: [...] De esta manera, el marco jurídico resulta complejo ya que, como se apuntó inicialmente, queda configurado de manera unitaria y sistemática por lo establecido por el texto constitucional unitaria y sistematica por lo establecido por el texto constitucional
y los valores y principios que incorpora, todo ello interpretado de conformidad con las sentencias del Tribunal Constitucional, así como también por lo establecido por los tratados y convenios internacionales relativos a los derechos humanos, en especial la Convención Americana de Derechos Humanos interpretada por la jurisprudencia de la Corte Interamericana de Derechos Humanos. Todo lo cual, en conjunto, viene a definir los parámetros que marcan de manera obligada e inexcusable las lineas a seguir por las normas legales, los tribunales de justicia, el Ministerio Público, la actuación del Gobierno y la administración, así como de las Fuerzas y Cuerpos de Seguridad. Asi, todas las instituciones y poderes públicos, sean de carácter legislativo, ejecutivo, jurisdiccional, institucional civil, policial, militar, estatal, regional o municipal que
} 
- Constitución.

- Jurisprudencia emitida por el Tribunal Constitucional.

- Tratados internacionales de derechos humanos

- Jurisprudencia de la Corte Interamericana de Derechos Humanos

Coincidiendo con éste segundo enfoque (la normativa constitucional) para definir el contenido constitucionalmente protegido de un derecho Abad, S. (2017) opina:

A nuestro juicio, para determinar el contenido constitucionalmente protegido de un derecho, entendido como una causal de improcedencia del amparo y no de fundabilidad, se debe tratar de delimitar los alcances del derecho fundamental que sustenta la demanda de amparo; es decir, el intérprete debe definir en qué consiste el derecho fundamental alegado y lo que no forma parte de aquel. Esto implica determinar los sujetos del mismo, las facultades o prestaciones que involucra; en definitiva delimitarlo. Para ello resulta indispensable acudir a lo dispuesto por los instrumentos internacionales sobre derechos humanos, la jurisprudencia de la Corte Interamericana de Derechos Humanos, así como los precedentes y la doctrina jurisprudencial del propio Tribunal Constitucional.

En igual sentido se pronuncia Castillo, L. (2006):

\section{[...] para el caso peruano, el contenido constitucional de los derechos constitucionales se configura según lo que la norma internacional sobre derechos humanos haya dispuesto del derecho o libertad cuyo contenido se intenta delimitar. No se puede formular el contenido constitucional de ningún derecho constitucional al margen de lo que las normas internacionales o resoluciones de Tribunales internacionales vinculantes para el Perú hayan dispuesto.}

participen directa o indirectamente en la lucha contra el terrorismo están en la obligación de adecuar sus actuaciones a lo definido en dichos parámetros o, en caso contrario, incurren en responsabilidad debiendo ser sancionados conforme a Derecho.
Como adelantamos el Tribunal Constitucional del Perú también ha aplicado este parámetro de constitucionalidad para configurar el contenido de un derecho constitucional en varios casos, que en nuestra opinión debería continuar y profundizar. Estimamos que no solo el TC debe aplicarlo, sino también los jueces constitucionales del Poder Judicial y los operadores jurídicos que acuden a la jurisdicción constitucional como demandante o demandados.

En el caso Blanca Estrella Cárdenas de la Torre, Exp. N. ${ }^{\circ}$ 661-2004-AA/TC, el Tribunal Constitucional configuró el contenido de la libertad de trabajo de la siguiente manera:

En esta oportunidad ampliaremos algunos alcances de este derecho. En efecto, la Constitución reconoce en el artículo $2^{\circ}$ inciso 15, que toda persona tiene derecho a trabajar libremente con sujeción a la ley. Conforme a la Cuarta Disposición Final y Transitoria de la Constitución, las normas relativas a los derechos y libertades que aquella reconoce se interpretan de conformidad con la Declaración Universal de los Derechos Humanos y los Tratados Internacionales sobre la misma materia ratificados por el Perú. (Fundamento 3)

En tal sentido, el artículo $23^{\circ}$ de la Declaración Universal de los Derechos Humanos reconoce que toda persona tiene derecho a la libre elección de su trabajo. A su turno, el artículo 6 del Pacto Internacional de Derechos Económicos, Sociales y Culturales consagra el derecho de toda persona a tener la oportunidad de ganarse la vida mediante un trabajo libremente escogido o aceptado. Por su parte, el Protocolo Adicional a la Convención Americana sobre Derechos Humanos en materia de Derechos Económicos, Sociales y Culturales, preceptúa en su artículo $7^{\circ}$, literal b), "el derecho de todo trabajador a seguir su vocación y a dedicarse a la actividad que mejor responda a sus expectativas y a cambiar de empleo, de acuerdo con la reglamentación nacional respectiva. (Fundamento 4)

En consecuencia, el derecho a la libertad de trabajo comprende de manera enunciativa: el derecho de todo trabajador 
The constitutionally protected content according to section 1 of article 5 of the Constitutional

Code of Procedure

a seguir su vocación $y$ a dedicarse a la actividad que mejor responda a sus expectativas, la libre elección del trabajo, la libertad para aceptar o no un trabajo y la libertad para cambiar de empleo [...] (Fundamento 5)

En el caso Víctor Ricardo Luna Mendoza y otros, Exp. N. ${ }^{\circ} 1875-2006-\mathrm{PA} / \mathrm{TC}$, se configuró el contenido del derecho a la igualdad y el principio de igualdad de oportunidades sin discriminación en los siguientes términos:

El inciso 2 del artículo $2^{\circ}$ de la Constitución dispone que toda persona tiene derecho a la igualdad ante la ley y que nadie puede ser discriminado por motivo de origen, raza, sexo, idioma, religión, opinión, condición económica o de cualquier otra indole [...] (Fundamento 5)

Por su parte, el inciso 1 del artículo $26^{\circ}$ de la Constitución reconoce que en la relación laboral se respeta el principio de igualdad de oportunidades sin discriminación. Es evidente que el reconocimiento constitucional de dicho principio laboral constituye una manifestación del derecho a la igualdad en el ámbito de las relaciones labores [...] (Fundamento 6)

Según lo establecido en la cuarta disposición final y transitoria de la Constitución; el artículo $V$ del Título Preliminar del Código Procesal Constitucional; los artículos 26, del Pacto Internacional de Derechos Civiles y Políticos; $1^{\circ}$ y $24^{\circ}$, de la Convención Americana de Derechos Humanos; $3^{\circ}$, del Protocolo de San Salvador, y $1^{\circ}$ y $3^{\circ}$, del Convenio N. ${ }^{\circ} 111$ de la Organización Internacional del Trabajo (OIT), relativo a la discriminación en materia de empleo $y$ ocupación, todos ellos ratificados por el Perú, que constituyen parámetro de interpretación constitucional, se proscribe cualquier trato discriminatorio. (Fundamento 8)

En el caso COSAPI S.A., Exp. N. ${ }^{\circ} 0785-2004-$ AA/TC, el Tribunal Constitucional configuró el contenido del derecho a la negociación colectiva de la siguiente manera:

En efecto, el artículo $28^{\circ}$ de la Constitución dispone que el Estado reconoce el derecho a la negociación colectiva, cautela su ejercicio democrático, fomenta la negociación colectiva y que la convención colectiva tiene fuerza vinculante en el ámbito de lo concertado. Conforme a la Cuarta Disposición Final y Transitoria de la Constitución, las normas relativas a los derechos y libertades que aquella reconoce se interpretan de conformidad con la Declaración Universal de los Derechos Humanos y los tratados internacionales sobre la misma materia ratificados por el Perú. (Fundamento 3)

Al respecto el Convenio $N .^{\circ} 98$ de la Organización Internacional del Trabajo relativo a la aplicación de los principios del derecho de sindicación y de negociación colectiva, aprobado por Resolución Legislativa $N .{ }^{\circ} 14712$ del 15 de noviembre de 1963, establece, en su artículo $4 .{ }^{\circ}$, que se deberán adoptar medidas adecuadas a las condiciones nacionales cuando ello sea necesario, para estimular y fomentar entre los empleadores y las organizaciones de empleadores, por una parte, y las organizaciones de trabajadores, por otra, el pleno desarrollo y uso de los procedimientos de negociación voluntaria, con objeto de reglamentar, por medio de contratos colectivos, las condiciones de empleo. (Fundamento 4)

Por tanto, el derecho constitucional a la negociación colectiva se expresa principalmente en el deber del Estado de fomentar y estimular la negociación colectiva entre los empleadores $y$ trabajadores, conforme a las condiciones nacionales, de modo que la convención colectiva que se deriva de la negociación colectiva tiene fuerza vinculante en el ámbito de lo concertado. (Fundamento 5)

Este Colegiado, por las consideraciones expuestas, ha precisado que: “(...) el artículo $28 .^{\circ}$ de la Constitución debe interpretarse en el sentido de que, si bien esta labor de fomento y promoción de la negociación colectiva, implica, entre otras acciones, que el Estado promueva las condiciones necesarias para que las partes negocien libremente, ante situaciones de diferenciación admisible, el Estado debe realizar determinadas acciones positivas para asegurar las posibilidades de desarrollo y efectividad de la negociación 
colectiva, pudiendo otorgar determinado "plus de tutela" cuando ésta sea la única vía para hacer posible la negociación colectiva". (Exp. N. ${ }^{\circ}$ 0261-2003-AA/TC, Fundamento $N .^{\circ}$ 3). (Fundamento 6 )

En el caso Sindicato de Trabajadores Mineros de Atacocha, Exp. N. ${ }^{\circ}$ 3311-2005-PA/TC, el Tribunal Constitucional configuró la libertad sindical en los siguientes términos:

El artículo $28^{\circ}$, inciso 1) de la Constitución reconoce el derecho de sindicación $y$ la libertad sindical. Al respecto, este Colegiado ha establecido que su contenido esencial tiene dos aspectos: el primero consiste en la facultad de toda persona de constituir sindicatos con el propósito de defender sus intereses gremiales, mientras que el segundo se refiere a la facultad de afiliarse o no afiliarse a este tipo de organizaciones. A su vez, se ha precisado que implica la protección del trabajador afiliado o sindicado frente a la comisión de actos que perjudiquen sus derechos y tengan como motivación real su condición de afiliado o no afiliado de un sindicato $u$ organización análoga. (Exp. N. ${ }^{\circ} 1124-2001-A A / T C$, Fundamento $\left.N{ }^{\circ} 8\right)$. Del mismo modo, en el citado caso, se dejó abierta la posibilidad de ulteriores concretizaciones del contenido esencial de la libertad sindical. (Fundamento 3)

En el Exp. N. ${ }^{\circ}$ 0008-2005-PI/TC, este Colegiado estableció que la libertad sindical no sólo tenía una dimensión individual, relativa a la constitución de un sindicato y a su afiliación, sino también una dimensión plural, que se manifiesta en la autonomía sindical y la personalidad jurídica (Fundamento $N .^{\circ}$ 26). Esta es la dimensión de la libertad sindical que deberá ser configurada en el presente caso. Para ello, aplicaremos la Cuarta Disposición Final y Transitoria de la Constitución y al artículo $V$ del Título Preliminar del Código Procesal Constitucional, que disponen que el contenido y alcances de los derechos $y$ libertades que aquella reconoce se interpretan de conformidad con la Declaración Universal de los Derechos Humanos y los tratados internacionales sobre la misma materia ratificados por el Perú. (Fundamento 4)
El artículo 3.1. del Convenio $N{ }^{\circ} 87$ de la OIT, relativo a la libertad sindical y a la protección del derecho de sindicación, precisa que las organizaciones de trabajadores tienen el derecho de elegir libremente a sus representantes, de organizar su administración y sus actividades y de formular su programa de acción. Por su parte el artículo 1.2. del Convenio $N{ }^{\circ} 98$ de la OIT, relativo a la aplicación de los principios del derecho de sindicación y de negociación colectiva, establece la protección de los trabajadores sindicalizados contra todo acto que tenga por objeto despedir a un trabajador o perjudicarlo en cualquier otra forma a causa de su afiliación sindical o de su participación en actividades sindicales fuera de las horas de trabajo, o con el consentimiento del empleador, durante las horas de trabajo. (Fundamento 5)

Por tanto, en esta oportunidad y a la luz del caso concreto, debe precisarse que la libertad sindical en su dimensión plural también protege la autonomía sindical, esto es, la posibilidad de que el sindicato pueda funcionar libremente sin injerencias o actos externos que lo afecten. Protege, asimismo, las actividades sindicales que desarrollan los sindicatos y sus afiliados de manera colectiva, así como la de los dirigentes sindicales para que puedan desempeñar sus funciones y cumplir con el mandato para el que fueron elegidos. (Fundamento 6)

\section{CONCLUSIÓN}

Como hemos podido comprobar a nivel de la doctrina nacional no hay consenso sobre el concepto de contenido constitucionalmente protegido; para unos es lo mismo que contenido esencial, para otros no. Por ello, a fin de clarificar una definición del contenido de un derecho primero se debería partir por nuestro marco normativo, Cuarta disposición final y transitoria de la Constitución y artículo V del Título Preliminar del Código Procesal Constitucional, que nos impone la obligación de encontrar el perfil y contenido de los derechos a partir de la Constitución, los tratados internacionales de derechos humanos, la jurisprudencia constitucional del TC y las decisiones de los Tribunales Internacionales de 
The constitutionally protected content according to section 1 of article 5 of the Constitutional

Code of Procedure

derechos humanos de los que el Perú es parte. Ésta postura es casi pacífica entre nosotros. En un segundo nivel se podrían adoptar determinadas posiciones doctrinarias, que en nuestro caso sugerimos seguir la propuesta de Freixes, T. (1998).

\section{BIBLIOGRAFÍA}

Abad, S. (2017) "El Proceso constitucional de amparo”, 3ra Ed., Lima: Gaceta Jurídica. Pág. $108,110$.

Castillo, L. (2006), El contenido constitucional de los derechos como objeto de protección del proceso de amparo, en: Palomino Manchego, J. El Derecho Procesal Constitucional Peruano (Estudios en homenaje a Domingo García Belaunde), Tomo I, Lima: Editora Jurídica Grijley. Pág. 583, 591-599.

Eto, G. (2013), "Tratado del Proceso Constitucional de Amparo”, Tomo I, Lima: Gaceta Jurídica.

Figueroa, E. (2015), "Comentario al inciso 1 del Artículo 5 del Código Procesal Constitucional", en: AAVV, Código Procesal Constitucional Comentado, Tomo I, Lima: Gaceta Jurídica. Pág. 148.

Freixes, T. (1998), “La Constitución y el sistema de derechos fundamentales y libertades públicas", en: AAVV, Administración Pública y Constitución. Reflexiones sobre el XX aniversario de la Constitución Española de 1978, Madrid: Instituto Nacional de Administración Pública. Pág. 156 y 157.
Mesía, C. (2013). "Exégesis del Código Procesal Constitucional", 4ta Ed., Tomo I, Lima, Gaceta Jurídica. Pág., 241.

Remotti, J. (2009), Prólogo. La lucha contra el terrorismo en el marco del Estado Social y Democrático de Derecho, en: Castañeda Segovia, Mateo G., El delito de terrorismo en garantías procesales en la lucha antiterrorista, Lima: Ed. Grijley.

\section{JURISPRUDENCIA CONSTITUCIONAL}

Caso COSAPI S.A., Exp. N. ${ }^{\circ} 0785-2004-A A /$ TC

Caso Blanca Estrella Cárdenas de la Torre, Exp. N. ${ }^{\circ}$ 661-2004-AA/TC

Caso Apolonia Collcca Ponce, Exp. N. ${ }^{\circ} 3179-$ 2004-AA/TC

Caso Anicama Hernández, Exp. N. ${ }^{\circ} 01417-$ 2005-AA/TC

Caso Sindicato de Trabajadores Mineros de Atacocha, Exp. N. ${ }^{\circ} 3311-2005-P A / T C$

Caso Víctor Ricardo Luna Mendoza y otros, Exp. N. ${ }^{\circ} 1875-2006-\mathrm{PA} / \mathrm{TC}$

Caso Gregorio Dennis Chávez de Paz, Exp. N. ${ }^{\circ} 02282-2013-\mathrm{PA} / \mathrm{TC}$ 